\title{
Decision making in a sequential search task
}

\author{
JAMES P. KAHAN, AMNON RAPOPORT ${ }^{2}$ AND LYLE V. JONES
}

UNIVERSITY OF NORTH CAROLINA

Ss were instructed to find the largest of a set of 200 different numbers, observed one at a time (when only the number currently observed could be declared the largest). Numbers sampled from one of three distributions, one with positive skew, one with negative skew, and one rectangular, were presented to three samples of $22 \mathrm{Ss}$, tested in small groups. The rectangular-distribution condition also was administered individually to a fourth sample of 22 Ss. Results failed to show effects of the distribution of numbers upon S's performance. However, as predicted, Ss tested in groups tended to observe more cards before stopping than those tested indvidually. Data are analyzed in an effort to evaluate the adequacy of altemative "stopping rules" as strategies descriptive of Ss performance.

In a sequence of observations, a decision maker might be instructed to select the best option. On each observation, he may decide to reject the observed option and continue the search, or to stop and accept the current option. He may not later choose an option he has previously rejected. Problems of this nature are known as stopping-rule problems (Breiman, 1964) and optimal stopping problems (Gilbert \& Mosteller, 1966). They resemble real-life problems such as accepting a job offer, buying a second-hand car, or selecting a marriage partner.

The present study is concerned with an optimal stopping problem with a fixed number of observations and no cost to the decision maker for making an observation. That is, given $\mathrm{N}$ different real numbers on cards, to be viewed in random order, one at a time, how can one maximize the probability of choosing the card with the largest number? Two rules govern play: (1) Only the current observation may be chosen as the largest number. (2) As the numbers are observed, the cards are turned up so that a comparison of the discards and the current observation is possible.

This game constitutes a finite Markov chain. We define the state $S_{n}$ as

$$
\mathrm{S}_{\mathrm{n}}=\max \left(\mathrm{X}_{1}, \mathrm{X}_{2}, \ldots, \mathrm{X}_{\mathrm{n}}\right),
$$

where $x_{n}$ is the number written on the $n^{\text {th }}$ card, $n=1,2, \ldots, N$. We then have

$$
\begin{aligned}
P\left(S_{n+1}=j \mid S_{n}=i\right) & =0 \text { for } j<i, \\
& =P\left(X_{n+1}=j\right) \text { for } j>i .
\end{aligned}
$$

A solution to the finite optimal stopping problem for large N was given by Ash and Jones (1964): Sample until $\mathrm{Z}_{\mathrm{O}}=\mathrm{N}-\mathrm{k}_{\mathrm{O}}$ cards have been observed, and then stop after exposing the first card which is the largest of those seen so far (hereafter referred to as a candidate). Declare the candidate to be the largest in the deck. The optimal number of remaining cards, $k_{0}$, is the smallest root of

$$
\left(1-\frac{k_{o}}{N}\right)\left(1 k_{j}^{k_{o}}-1 \frac{1}{N-j}\right)=\frac{1}{N} \text {. }
$$

This is given to good approximation for large $\mathrm{N}$ by

$$
k_{0} \approx N\left(1-\frac{1}{e}\right) ;
$$

then,

$$
\mathrm{z}_{\mathrm{O}} \approx \mathrm{N} / \mathrm{e} .
$$

Gilbert and Mosteller (1966) provide exact values of $\mathrm{Z}_{\mathrm{O}}$ for different values of $\mathrm{N}$.

Using the optimal stopping rule as a base line, we wish to assess discrepancies of empirical results from optimality, noting any systematic differences which may suggest models better able to account for the observed behavior. In addition, two experimental variables are studied specifically. (1) What is the effect of the distribution of numbers upon the decision maker's strategy? In the derivation of the optimal stopping rule, no assumption is made about the distribution of offers. However, distributions differing in variance and skewness might be expected to yield differences in search behavior. (2) What is the effect of individual vs group administration of the task? It is hypothesized that Ss tested in groups will stop later than Ss tested individually. In the individual situation, the experiment ends as soon as S stops; in the group situation he must remain until the slowest member of the group finishes. The cost of observations is therefore more likely to be salient for the Ss tested alone, an effect that would lower the optimal stopping number $\mathrm{Z}_{\mathrm{O}}$ (Ash \& Jones, 1964; Rapoport \& Tversky, 1966). Also, in a group, it may be embarrassing for $S$ to stop too soon while others continue and win. Thus, he may choose to avoid early stopping.

\section{Method}

Ss were 88 summer students from introductory psychology at the University of North Carolina, who volunteered for a decision-making experiment to fulfill a course requirement. They were told that they might earn a monetary award. Sixty-six Ss met in 
Table 1. Distribution of stopping point for all conditions

\begin{tabular}{ccccc} 
Condition & $Z<74$ & $74 \leq Z<200$ & $Z=200$ & Total \\
\hline$A$ & 1 & 6 & 15 & 22 \\
B & 3 & 9 & 10 & 22 \\
$C$ & 2 & 8 & 12 & 22 \\
$D$ & 6 & 10 & 6 & 22 \\
Total & 12 & 33 & 43 & 88 \\
\hline
\end{tabular}

groups of from two to six members, randomly assigned to experimental conditions, A, B, and C, with $22 \mathrm{Ss}$ in each. Each $S$ was given a set of 200 numbers written on $3 \times 5$ cards. For Condition A, numbers had been sampled from a Beta distribution, $g_{A}$, with parameters $a=1, b=2$, a positively skewed triangular distribution. Condition B was another Beta distribution, $g_{B}$, with parameters $a=2, b=1$, a negatively skewed triangular distribution (the mirror image of $\mathrm{g}_{\mathrm{A}}$ ). Condition $\mathrm{C}$ was a rectangular distribution, $\mathrm{g}_{\mathrm{C}}$, a Beta distribution with $a=1, b=1$. All three distributions were adjusted to have mean 1250. The standard deviations of $\mathrm{g}_{\mathrm{A}}, \mathrm{g}_{\mathrm{B}}$, and $\mathrm{g}_{\mathrm{C}}$ were $884,442,722$, respectively. The $22 \mathrm{Ss}$ in Condition $\mathrm{D}$ received exactly the same instructions and the same distribution as Condition $\mathrm{C}$, but were met individually.

The deck of 200 cards was shuffled and placed face down in front of $S_{9}$ who was told that the numbers represented offers for some stocks he was to sell. Each $S$ was instructed to turn one card at a time, to record its number, and for each card either to declare this observation to be the largest offer in the deck, or to reject it and turn up another card. An S was paid 2 dollars if he chose the highest card and nothing if he did not.

\section{Results}

Let $Z, Z=1,2, \ldots, 200$, denote the number of cards observed by $S$ before stopping the search. If an $S$ failed to select the actual highest number when he saw it, he passed through the remainder of the deck without seeing another candidate and was assigned a $\mathrm{Z}$ of 200 . For Conditions $\mathrm{A}, \mathrm{B}$, and $\mathrm{C}$, the mean $\mathrm{Z}$ was 177.9 , 155.0 , and 156.0 , respectively, with corresponding standard deviations $41.5,48.7$, and 50.9. Using a oneway analysis of variance, the means were not significantly different $(F=1.57, \mathrm{df}=2 / 63, .25>p>.10)$. Thus, there is insufficient evidence to reject the hypothesis of equal stopping points in the three treatment populations.

The effect of the testing situation was examined by comparing Conditions $\mathrm{C}$ and $\mathrm{D}$, with means of 156.0 and 122.4, respectively, and standard deviations of 50.9 and 64.0 . The null hypothesis of equal population means was rejected, using a one-tailed $t$ test $(t=1.93$, df $=42, p<.05$ ).

\section{Discussion}

The optimal stopping rule prescribes an optimal stopping number,

$$
\mathrm{Z} \approx \frac{200}{\mathrm{e}} \approx 74
$$

Ss in each condition were divided accordingly into three subgroups, depending on whether $\mathrm{Z}<74,74 \leq \mathrm{Z}<$ 200 , or $Z=200$ (Table 1). To assess the descriptive adequacy of the optimal stopping rule, it was tested with the data obtained from each $\mathrm{S}$. The number of optimal Ss for each group and stopping-point interval appears in Table 2 .

An $S$ can be nonoptimal by stopping too soon $(Z<74)$ or by passing a candidate that should be taken $(Z>74)$. Differences between entries in Table 1 and Table 2 show that most of the nonoptimal Ss in Conditions A, B, and $\mathrm{C}$ did not stop soon enough, having rejected a candidate that should have been accepted. In Condition $\mathrm{D}$, on the other hand, six out of 11 nonoptimal Ss accepted candidates too early.

The optimal stopping rule fails to describe the behavior of $1 / 3$ to $1 / 2$ of all Ss. One reason for its inadequacy may be that the rule is not strictly applicable to the task in this study. To clarify, we distinguish between two extreme variations of the task. The first is a "known-distribution" problem, with the numbers randomly sampled from a distribution completely known to S. Here, "no buildup of experience is needed to set a standard, and a profitable choice can sometimes be made immediately" (Gilbert \& Mosteller, 1966, p. 52). The second variation is a "distributionfree" problem, in which, rather than seeing the numbers, the $S$ is told the rank of the current card among the numbers appearing on cards drawn previously. He must select or reject candidates (cards of rank one) solely on the basis of that information.

Optimal stopping rules for both variations were derived by Gilbert and Mosteller. For the distributionfree problem the mule is exactly the same as described above, with $\mathrm{Z}_{\mathrm{o}} \approx \mathrm{N} / \mathrm{e}$. For the known distribution problem, the rule is stated in terms of decision numbers $d_{i}$. where $i$ is the number of the draw, such that $s$ chooses a candidate on draw $i$ if and only if it is larger than $d_{i}$. A simpler strategy for the known-distribution problem also given by Gilbert and Mosteller, employs the use of two decision numbers, $d$ and 0 , with $d_{1}=$ $d_{2}=\ldots=d_{t}=d$, and $d_{t+1}=d_{t+2}=\ldots=d_{n}=0$. Gilbert and Mosteller report that with an appropriate $d$, and a choice of $t=N / 2$, the asymptotic probability of winning is .551 , as compared with optimal .580 .

The present task is considered to fall between the

Table 2. Frequency of optimal performance depending on condition and stopping point

\begin{tabular}{ccccc} 
Condition & $Z<74$ & $74 \leq Z<200$ & $Z=200$ & Total \\
\hline A & 0 & 6 & 6 & 12 \\
B & 0 & 6 & 8 & 14 \\
C & 0 & 8 & 7 & 15 \\
D & 0 & 5 & 6 & 11 \\
Total & 0 & 25 & 27 & 52 \\
\hline
\end{tabular}


Table 3. The subjective cut-off model

\begin{tabular}{ccccc} 
Condition & $\begin{array}{c}\text { Ss follow- } \\
\text { ing model }\end{array}$ & $\begin{array}{c}\text { Type 1 } \\
\text { violators }\end{array}$ & $\begin{array}{c}\text { Type 2 } \\
\text { violators }\end{array}$ & $\begin{array}{r}\text { Type 3 } \\
\text { violators }\end{array}$ \\
\hline A & 19 & 0 & 0 & 3 \\
B & 20 & 0 & 0 & 2 \\
C & 16 & 0 & 3 & 3 \\
D & 20 & 1 & 1 & 0 \\
Total & 75 & 1 & 4 & 8 \\
\hline
\end{tabular}

two extreme versions just described. Ss do not have complete knowledge of the distribution of offers, but they do learn more than just the rank order of an offer. With no initial idea of the distribution of a sequence of offers, S should pass early offers, merely observing them to estimate the distribution.

These considerations, along with Gilbert and Mosteller's simple strategy, suggest a model which takes into account the actual sequence of offers observed by $S$, and assumes a subjective cut-off point that corresponds to the theoretical d discussed above. The model prescribes taking the first candidate that is at least $\mathrm{M}^{*}$ standard deviations from the mean of the previous offers. Formally, if the $j$ th offer, $j=n$, $n+1, \ldots N$, is a candidate, and is $M_{j}$ standard deviations from the mean $\mu_{j}$, it should be selected if and only if $M_{j} \geq M^{*}$. After $N / 2$ observations, any candidate should be chosen. The model is violated If $S$ stops at the $j$ th offer and there was some previous candidate $i$ for which $M_{j}>M_{j}$, or if $S$ fails to select a candidate observed after the first $N / 2$ offers.
This subjective-cutoff model is tested with an arbitrarily selected $n=20$; $1 . e .$, it is assumed that 20 observations are made prior to setting $M^{*}$. Results are in Table 3. Violations from the model were classified into three types, selecting a candidate before the 20th offer (Type 1), selecting a candidate before offer 100 that did not have a maximum $M_{j}$ (Type 2), or passing a candidate observed after 100 cards had been seen (Type 3). As can be seen from Table 3 , the subjective-cutoff model was satisfied by 75 of the $88 \mathrm{Ss}$. This result encourages further exploration of this class of models. In particular, it is desired to develop a rationale for selecting the cutoff point, $n$, and to determine how the distribution of observed offers might affect both $n$ and the decision number $\mathrm{M} *$ 。

\section{References}

Ash, M., \& Jones, W. Optimai strategies for maximum-number games. J. math. Anal. Applic., 1964, 9, 138-140.

Brieman, L. Stopping-rule problems. In E. F. Beckenback (Ed.), Applied combinatorial mathematics. New York: Wiley, 1964. Pp. 284-319.

Gilbert, J. P., \& Mosteller, F. Recognizing the maximum of a sequence. J. Amer. Statist. Ass., 1966, 61, 35-73.

Rapoport, A., \& Tversky, A. Cost and accessibility of offers as determinahts of optimal stopping. Psychon. Sci, 1966, 4, 145-146.

\section{Noies}

1. Supported by NIH Grant No. M-10006.

2. Now at Hebrew University, Jerusalem, Israel.

(Accepted for publication April 18, 1967.) 